\title{
Analysis of minimum ignition temperature of pellet dust layer and cloud due to adding BC and $A B C$ fire extinguishing powders
}

\author{
Bożena Kukfisz ${ }^{1, *}$ \\ ${ }^{1}$ The Main School of Fire Service, Faculty of Fire Safety Engineering, 52/54 Slowackiego St., 01-629 \\ Warsaw, Poland
}

\begin{abstract}
The paper describes the impact of adding fire extinguishing powders acting based on oxygen or flame on values of minimum ignition temperatures of the layer and cloud of pellet dust, and as a consequence the impact or lack of impact on values of maximum admissible temperature on external surfaces of electrical appliances working in their atmospheres. Tests were conducted of the minimum ignition temperature of layer and cloud of the agro armakow pellet dust and the agro jesien pellet dust, with and without additives of fire extinguishing powders BC Jet, BC LB2, ABC 90 and Ogniotex 103 at concentrations ranging from 5 to $70 \%$ by weight of powder contents in the mixture. Based on obtained test results it has been ascertained that type $\mathrm{ABC}$ powders appear to be much more effective than those type $\mathrm{BC}$, because they have a much bigger impact on increasing the minimum ignition temperature of the layer and the cloud of analysed dust types. Adding only $15 \%$ of $\mathrm{ABC} 90$ extinguishing powder to the agro jesien pellet has caused an increase in the minimum ignition temperature of dust layer by $80^{\circ} \mathrm{C}$. The BC LB2 powder with agro armakow pellet dust has not been found to cause any changes, even at its concentration as high as $70 \%$. The most optimum additive of powder to the biomass dust was $10 \%$ by weight of $\mathrm{ABC}$ powder in the mixture. At this concentration the highest increase was recorded in the maximum admissible temperature on the outer surface of electrical appliances from $235^{\circ} \mathrm{C}$ to $273^{\circ} \mathrm{C}$.
\end{abstract}

\section{Combustion with fire extinguishing powders}

Prior to its use in industry, biomass is generally stockpiled on storage areas, and afterwards hauled to appropriate processing plants, where it is subjected to processing to generate energy. In each of the above mentioned stages the biofuel comes into contact with the air, during which processes of intensive or slow oxidation, self-ignition or ignition take place. This may give rise to such undesired phenomena, as fires or explosions. What is more, oxidation is unfavourable due to a decrease in calorific value of stocked biomass [1].

Pursuant to the definition contained in PN-EN 615:2009 [2], a fire extinguishing powder is an extinguishing agent in the form of highly granulated solid chemical agents, consisting of one or a few basic ingredients and admixtures improving its properties. The

\footnotetext{
* Corresponding author: bkukfisz@sgsp.edu.pl
} 
main division of the powders arises from the type of their application. Three types of fire extinguishing powders may be distinguished:

- $\mathrm{ABC}$ - powders designated to extinguish fires of solid materials (group A, as a rule or organic origin), fires of liquids (group B), and fires of gases (group C).

- $\mathrm{BC}$ - powders designated for extinguishing fires groups $\mathrm{B}$ and $\mathrm{C}$.

- D - called special powders, which are designated for extinguishing metal fires (group D).

The biggest difference in the breakdown of powders is their chemical composition. Powders type $\mathrm{ABC}$ have a different active substance than in the case of $\mathrm{BC}$ type powders or D. Furthermore, each powder has several additives that enhance is properties. Table 1 presents the chemical composition of diverse types of fire extinguishing powders.

Table 1. Chemical composition of diverse types of fire extinguishing powders [3, 4].

\begin{tabular}{|c|c|c|}
\hline BC & ABC & D \\
\hline $\begin{array}{c}\text { Sodium hydrogencarbonate } \\
(\mathrm{NaHCO})\end{array}$ & & \\
Potassium hydrogen carbonate & & Sodium chloride $(\mathrm{NaCl})$ \\
$\left(\mathrm{KHCO}_{3}\right)$ & $\begin{array}{c}\text { Monoammonium phosphate } \\
\text { Potassium chloride }(\mathrm{KCl})\end{array}$ \\
$\begin{array}{c}\text { Potassium sulphate }\left(\mathrm{K}_{2} \mathrm{SO}_{4}\right) \\
\text { Urea }+ \text { Potassium hydrogen } \\
\text { carbonate }\left(\mathrm{NH}_{2} \mathrm{CONH}_{2}+\right.\end{array}$ & (NH4H2PO4+(NH4)2SO4) \\
$\left.\mathrm{KHCO}_{3}\right)$ & & Copper powder \\
\hline
\end{tabular}

\subsection{Setting out minimum combustion temperatures of pellet dusts with admixture of extinguishing powders $B C$ and $A B C$ - description of research methods}

From the viewpoint of passive explosion protection the minimum ignition temperature of dust layer is a very important element, which nevertheless is frequently being neglected [5]. There are numerous publications available pertaining to the delimitation of this parameter in the function of layer thickness, in the function of variable value of an increase in temperature of the heating furnace (e.g. CTHP constant temperature of the heated plate or CRHG constant rate of heat generation), works related to the development of a mathematical model, works related to correlation of determination of the minimum ignition temperature of dust layer (MITDL) based on the minimum ignition temperature of a dust cloud (MITDC) with the use of the Biot number, however, none of the analysed papers took into account the involvement of fire extinguishing powders, hence the attempt of taking up this particular issue specified in paper [6-12].

In the experimental part two types of organic biomass dusts have been selected for needs of trials: dust of the agro armakow pellet and dust of the agro jesien pellet, as well as four fire extinguishing powders: BC Jet, BC LB2, ABC 90 and Ogniotex 103. The dusts were chosen taking into consideration their varied fraction. The selection of fire extinguishing powders depends on their application. Two of them: BC Jet and BC LB2 are type BC powders, which act exclusively on flame. ABC 90 and Ogniotex 103 are type ABC powders, which act both on flame and on oxygen. For needs of testing prepared were homogenous mixtures of the above mentioned biomass dusts with fire extinguishing powders in proportions ranging from $5 \%$ to $70 \%$ by weight of powder in the mixture, and then parameters for each of the mixtures have been determined, such as the minimum ignition temperature of dust layer MITDL $\left[{ }^{\circ} \mathrm{C}\right]$, i.e. the lowest temperature of the hot surface, at which the dust layer present on it becomes ignited, with the layer having a specified thickness and the minimum ignition temperature of a dust cloud MITDC $\left[{ }^{\circ} \mathrm{C}\right]$, and namely the lowest temperature of the hot interior wall of the furnace, at which a dust cloud 
becomes ignited, in the air contained inside the furnace in accordance with the standard PNEN 50281:2002 Electrical apparatus for use in the presence of combustible dust - Part 2-1: Testing methods - Determination methods of minimum dust ignition temperature (method $\mathrm{A}$ and $\mathrm{B})$ [13].

\subsection{Analysis of impact of adding fire extinguishing powders on values of minimum ignition temperature of pellet layer and dust cloud}

To illustrate the impact that adding fire extinguishing powders exerts on values of the minimum ignition temperature of dust layer and cloud, use was made of four characteristics. Diagrams shown on figures 1 and 2 illustrate the impact of adding fire extinguishing powders BC Jet, BC LB2, ABC 90 and Ogniotex 103 on the value of minimum ignition temperature of the dust layer of the argo armakow pellet and the agro jesień pellet.

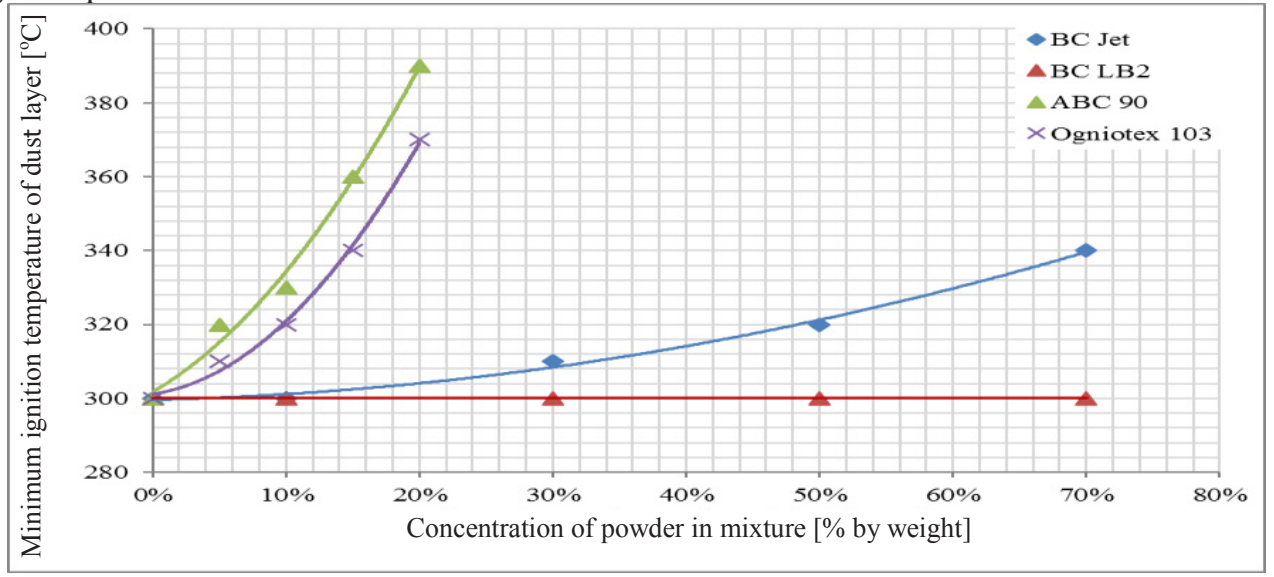

Fig. 1. Diagram showing the minimum ignition temperature value for layer of a mixture of powder with agro armakow pellet biomass $5 \mathrm{~mm}$ thick in the function of concentration of the fire extinguishing powder.

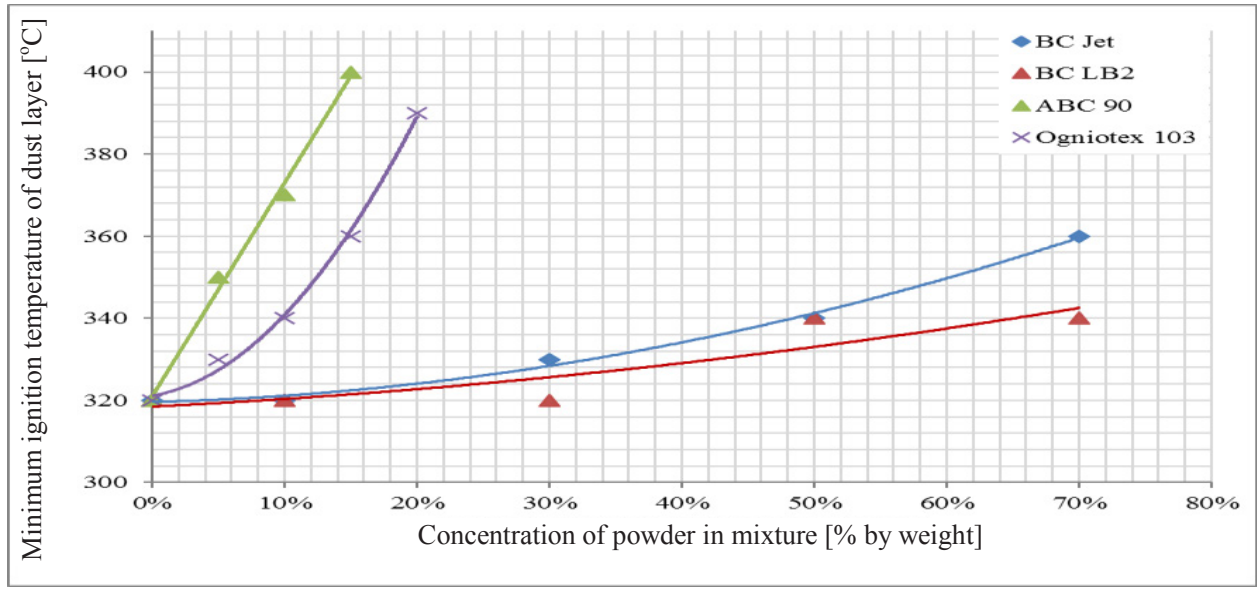

Fig. 2. Diagram showing the minimum ignition temperature value for layer of a mixture of powder with agro jesien pellet biomass $5 \mathrm{~mm}$ thick in the function of concentration of the fire extinguishing powder. 
Figures 3 and 4 illustrate the impact of the same powders on the value of minimum ignition temperature of the above mentioned dusts. On the vertical axis marked were values of MITDL or MITDC, and on the horizontal one - weight concentrations of powder in the mixture.

The characteristics show in a graphical way which powder is the most effective for increasing the values of the minimum ignition temperature of dust layer and dust cloud, and allow the determination of the most effective type of powder.

The biggest increase in the value of the minimum ignition temperature of biomass dust layer was recorded when an admixture of the $\mathrm{ABC} 90$ powder has been made. Already at its concentration amounting to $15 \%$ in a mixture with dust of the agro jesien pellet, ignition did not take place at the temperature of $400^{\circ} \mathrm{C}$. This is the maximum temperature of the plate for which tests are carried out in accordance with the standard. The lowest impact on MITDL was exerted by the BC LB2 powder. Even in the case of its $70 \%$ concentration in the mixture with the dust of the agro armakow pellet, ignition has been recorded at the same temperature as in the case of testing of pure biomass. Both tested powders of the type ABC, with both types of biomass differing as regards their fraction, bulk density and properties, caused a higher increase in the value of the minimum ignition temperature of dust layer, than type $\mathrm{BC}$ powders. At an addition of $20 \%$ of powder to biomass dust, MITDL tended to grow: for powders type $\mathrm{ABC}$ - from 70 to $90^{\circ} \mathrm{C}$, and for $\mathrm{BC}$ powders - from 0 to ca. $5^{\circ} \mathrm{C}$.

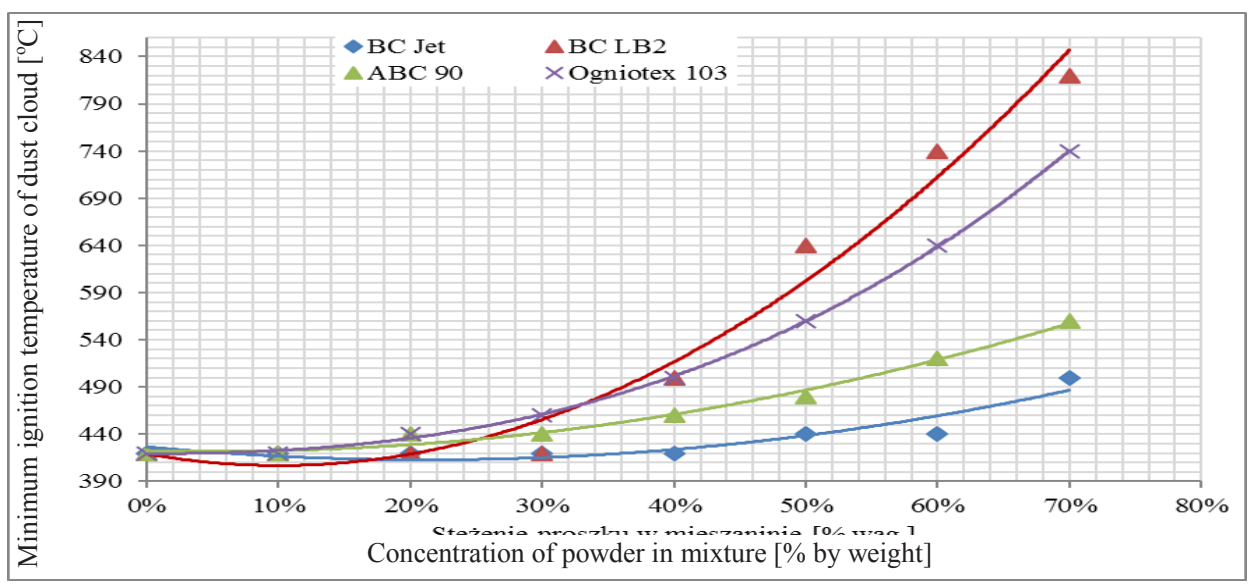

Fig. 3. Diagram showing the minimum ignition temperature of a cloud of a mixture of powder with biomass agro armakow pellet in the function of concentration of the fire extinguishing powder. 


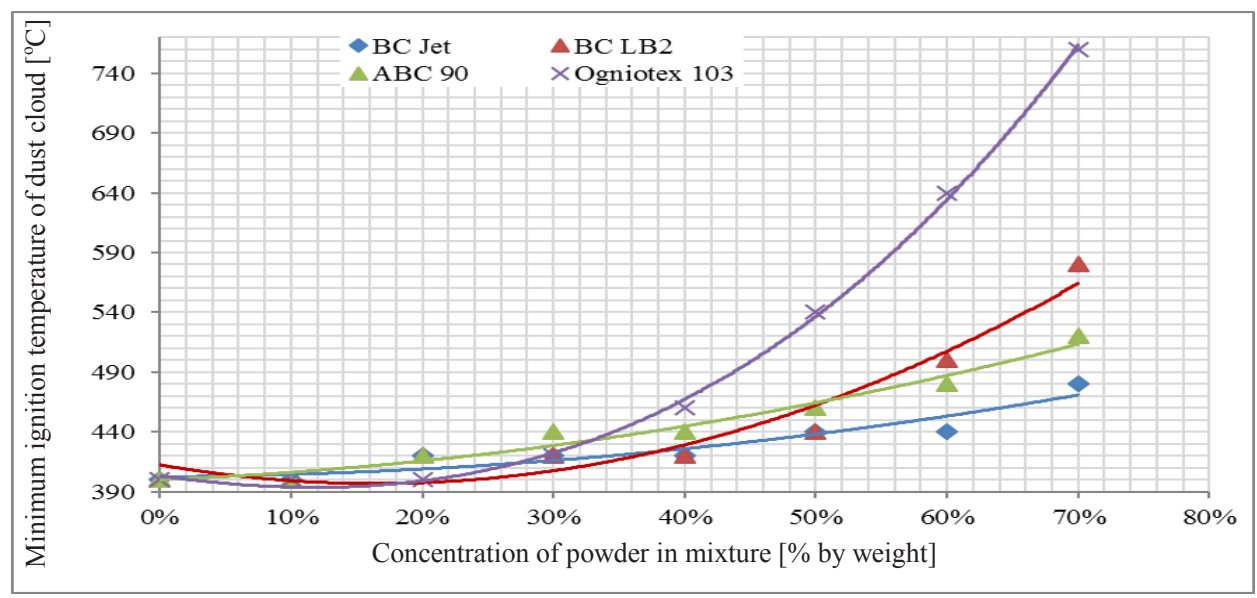

Fig. 4. Diagram showing the minimum ignition temperature of a cloud of mixture of powder with biomass agro jesien pellet in the function of concentration of the fire extinguishing powder.

In tests of the minimum ignition temperature of a cloud containing a mixture of biomass dusts with powders, a significant increase in temperature could be achieved not earlier than at high concentrations of fire extinguishing powders, reaching $40-50 \%$. The most advantageous influence on raising the MITDC of the dust of the agro armakow pellet was exerted by the BC LB2 powder, and of the dust of agro jesien pellet - Ogniotex 103. Their noticeable impact, i.e. an impact by over $40^{\circ} \mathrm{C}$, has nevertheless been achieved at a concentration of $40 \%$. The least marked impact on the minimum ignition temperature of dust cloud for both biomass types was exerted by BC Jet fire extinguishing powder.

The most evident impact of an addition of powders to biomass dusts was ascertained at maximum concentrations tested, i.e. the addition of $70 \%$ by weight of powder to biomass. The minimum ignition temperature of a cloud of agro armakow pellet dust, following addition of $70 \%$ by weight of BC LB2 powder led to an increase in MITDC from $420^{\circ} \mathrm{C}$ to $820^{\circ} \mathrm{C}$, and the dust of the agro jesien pellet from 400 to $760^{\circ} \mathrm{C}$, after addition of Ogniotex 103 powder.

In accordance with the standard the maximum admissible temperature of outer surface was set out for an electrical appliance working in the presence of flammable dusts, while table 2 presented values of maximum admissible temperatures of outer surface of an electrical appliance working in the presence of tested biomass dusts.

Table 2. Maximum admissible temperature of outer surface of an electrical appliance operating in the presence of a cloud and a layer of two types of biomass dust.

\begin{tabular}{|l|c|c|}
\hline \multirow{2}{*}{ Proprietary dust name } & \multicolumn{2}{|l|}{$\begin{array}{l}\text { Maximum admissible temperature of outer surface of an } \\
\text { electrical appliance (MATOSE) }\end{array}\left[^{\circ} \mathbf{C}\right]$} \\
\cline { 2 - 3 } & Layer & Cloud \\
\hline agro armakow & 225.00 & 280.00 \\
\hline agro jesień & 245.00 & 266.67 \\
\hline Average value for both dusts & 235.00 & 273.33 \\
\hline
\end{tabular}

The maximum admissible temperature of electrical appliances comprises two values. The first one of them is the minimum ignition temperature of a dust layer, and the second one - the minimum ignition temperature of its cloud. Those experimentally determined temperature values differ for the same dust and powder mixtures. In addition values of MATOSE for the layer accumulated on the apparatus and for the occurrence of a cloud are 
calculated based on different formulas. Those two elements cause considerable differences between both values. As a rule the generated dust cloud falls and becomes settled forming a layer on diverse types of substrates. Under the impact of slight air movements or if a heavy object falls, dust accumulated in this way is raised and forms suspensions in the air. Those phenomena occur practically in a joint way. Hence the maximum admissible temperature of the surface of an appliance as a rule depends on the lower of the two calculated MATOSE values.

Figure 5 and 6 presented values of MATOSE in relation to concentrations by weight of powders in the mixture. In order to achieve better transparency of the obtained results, a calculation was made of average values from measurements for dusts of agro armakow pellet and agro jesień pellet. Results of determination of MATOSE have been specified separately for a layer and for a cloud.

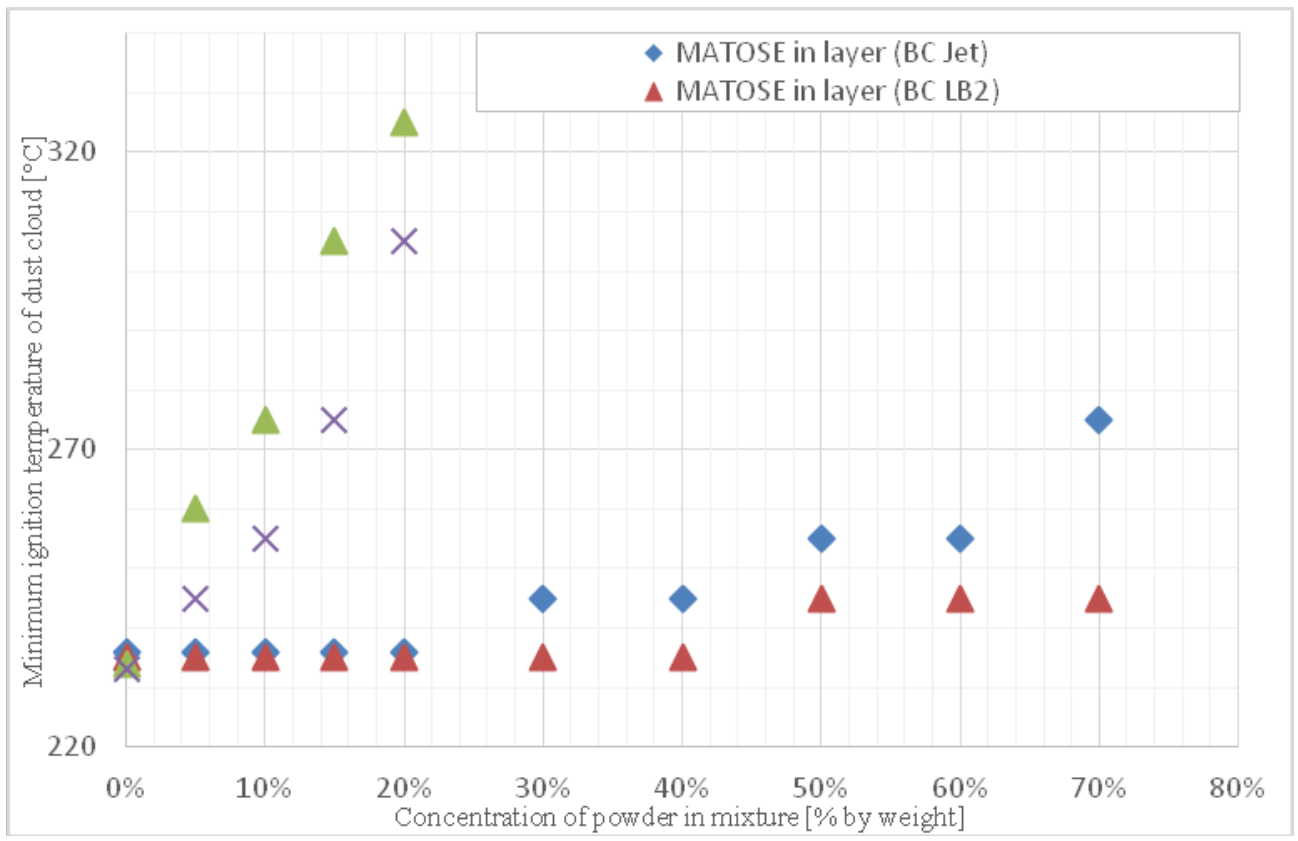

Fig. 5. Diagram showing the maximum admissible temperature of outer surface of an electrical appliance working in contact with flammable dusts MATOSE following addition to fire extinguishing powder. 


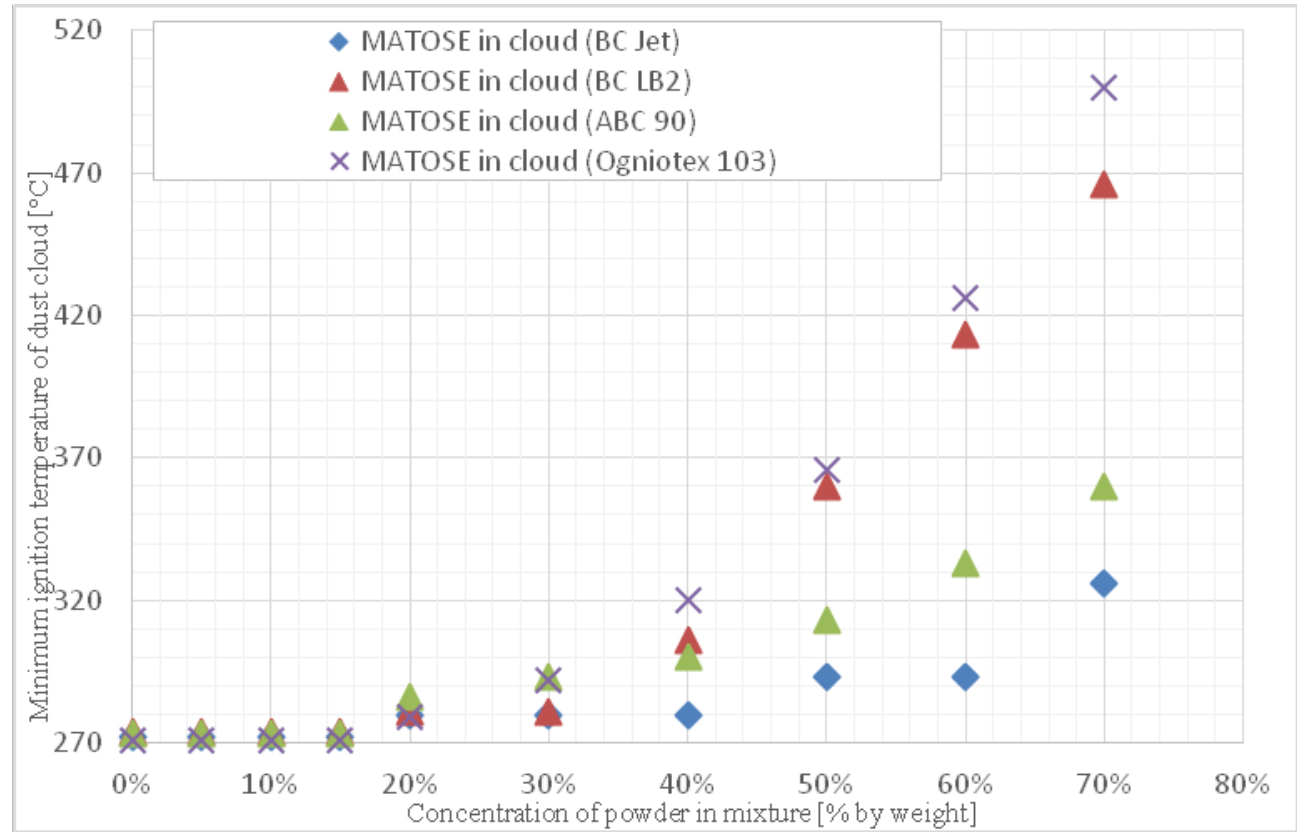

Fig. 6. Diagram showing the maximum admissible temperature of outer surface of an electrical appliance working in contact with flammable cloud MATOSE following addition to fire extinguishing powder

Apart from the fact that phenomena involving the occurrence of a cloud and accumulation of dust take place practically inseparably, it has been ascertained that addition of only $20 \%$ by weight of any of the tested ABC powders to the layer of biomass dust accumulated on an electrical appliance with a thickness up to $5 \mathrm{~mm}$, would increase the maximum admissible temperature of outer surface from $70^{\circ} \mathrm{C}$ to even $90^{\circ} \mathrm{C}$. This causes a maximum increase of MATOSE equalling to $38 \%$ as compared to pure biomass. Adding such an amount of $\mathrm{BC}$ powders would not lead to an increase in the minimum ignition temperature of layer, and consequently would not change the maximum admissible temperature of outer surface of an electrical appliance. If merely a cloud occurs, it is impossible to ascertain unambiguously which type of powder is more effective. Addition to the biomass dust of $70 \%$ by weight of Ogniotex 103 powder, i.e. type ABC powder, causes an increase of the maximum admissible temperature of outer surface of an electrical appliance, on average by $225^{\circ} \mathrm{C}$. At an identical concentration the $\mathrm{BC}$ LB2 powder causes an average increase of MATOSE by ca. $193^{\circ} \mathrm{C}$.

To allow selecting the most effective powder and to determine its optimum additive value to the biomass dust, i.e. the lowest concentration in the mixture, at which the maximum admissible temperature of outer surface of an electrical appliance would be the highest, use was made of a schema, and namely a comparison has been made of average MATOSE values from figure 5 and 6 , for layer and for cloud, separately for each of powder concentrations in the mixture. Given the fact that the final value of MATOSE is determined by the lowest of two values (for cloud and for layer), and that the average value of MATOSE for the occurrence of a pure biomass dust cloud is ca. $273^{\circ} \mathrm{C}$, and for a layer $235^{\circ} \mathrm{C}$, a powder was selected which would cause the quickest equalisation of both calculated temperatures at the lowest concentration. In such a way, powder ABC 90 was selected as the most effective one, and it was found that its optimum concentration equals to $10 \%$. At such a concentration the maximum admissible temperature on the outer surface 
of an appliance grew from 235 to $273^{\circ} \mathrm{C}$, i.e. by ca. $16 \%$. The Ogniotex 103 powder was found to achieve the same parameters as $\mathrm{ABC} 90$, however, at a concentration of $15 \%$ by weight in the mixture. Despite the fact that at the concentration of $10 \%$ none of the tested powders caused an increase in MATOSE at the presence of a dust cloud, taking into account a component also from the layer, $\mathrm{ABC} 90$ proved to be the most effective. An analysis of a $20 \%$ concentration of added powder has shown that also the ABC 90 powder proved to be just as effective. The value of MATOSE in this concentration grew from 235 to $286^{\circ} \mathrm{C}$, i.e. by ca. $21.5 \%$.

\section{Summary of results of conducted studies}

To sum up the impact of an admixture of fire extinguishing powders on values of the minimum ignition temperature of biomass dust layer, a significant impact was recorded for ABC type powders. Their $20 \%$ concentrations in the mixture caused an increase of MITDL ranging from 70 to $90^{\circ} \mathrm{C}$, depending on the tested powder. A comparison of the obtained results with fire parameters of pure biomass has shown an increase in MITDL of even 30\% for the dust of agro armakow pellet with the ABC 90 powder. If powders acting on flame are added to biomass dust affected insignificantly the minimum ignition temperature of their layer. Its contents of $30 \%$ in the tested mixture with any biomass type led to a maximum increase in the minimum ignition temperature of its layer of $10^{\circ} \mathrm{C}$. The highest studied concentrations, i.e. $70 \% \mathrm{~b}$ weight of powder in a mixture, caused an increase in MITDL maximally by $40^{\circ} \mathrm{C}$, which equals to ca. $13 \%$ as compared to pure biomass dust. The advantage of type $\mathrm{ABC}$ powders over $\mathrm{BC}$ in combustion of dusts forming a layer arises from the impact of the active factor on combustion of solid materials. $90 \%$ of ABC 90 is constituted by monoammonium phosphate. Ogniotex 103 contains $40 \%$ of ammonium phosphate and 52\% ammonium sulphate. Powders BC LB2 and BC Jet contain more than $95 \%$ sodium hydrogencarbonate in their chemical composition. Ammonium phosphates and sulphates may form an insulating layer on the surface of a solid, and apart from that react with wood-based materials, hindering their lighting up. Owing to those properties they have a consi-derable advantage over type $\mathrm{ABC}$ powders in combustion of a dust layer.

In search of a powder the addition of which would offer the most advantageous properties it has been ascertained that the $\mathrm{ABC}$ fire extinguishing powder type is much more effective as compared to type $\mathrm{BC}$. Of the two tested powders reacting to oxygen, $\mathrm{ABC} 90$ proved to be slightly superior to Ogniotex 103. Both powders differ as regards the quantitative and qualitative composition. The optimum concentration which should be added to dust to achieve the highest admissible temperature of the surface of electrical appliances, taking into account the economic factor (increase in biomass mass, cost of adding extinguishing powder) and fire risk (biomass management as a fuel with different physical and chemical properties in power plants, heating plants and combined heat and power plants, which were adapted for combustion only conventional fuel contributes for creating hazardous zones) are $10 \%$ by weight. At such concentration of $\mathrm{ABC} 90$ powder the admissible temperature of the surface of electrical appliances increases on average from 235 to $273^{\circ} \mathrm{C}$. As compared to powders of the $\mathrm{BC}$ type, at such a concentration they would not cause any change. To achieve an increase comparable with $\mathrm{ABC}$ powders, it would be necessary to add as much as $70 \%$ by weight of BC Jet powder to biomass, and even at that concentration powder BC LB2 would not be likely to cause an increase in MATOSE at such a level. 


\section{References}

1. W. Rybak, Combustion and co-combustion of solid biofuels (Printing house of Wroclaw University of Technology, 2006)

2. PN-EN 615:2009

3. T. Ostrowski, Dust explosion in the industry (The CRZZ Publishing Institute, 1980)

4. A. Mizerski, M. Sobolewski, Extinguishing media. Laboratory exercises (Publisher of the Main School of Fire Service, 1997)

5. P.R. Amyotte, Process Saf. Environ. 92, 292 (2014)

6. B. Burczyk, Biomass. Raw material for chemical syntheses and fuel production. (Printing house of Wroclaw University of Technology, 2011)

7. J.M. Jones, A. Saddawi, B. Dooley, E.J.S. Mitchell, J. Werner, D.J. Waldron, S. Weatherstone, and A. Williams, Fuel Process. Technol. 134, 372 (2015)

8. J. Dai, H. Cui, R.T. Grace, Prog. Energ. Combust. 38, 717 (2012)

9. E. Danzi, L. Marmo, D. Riccio, J. Loss Prevent. Proc. 36, 326 (2015)

10. E. K. Addai, G. Dieter, K. Ulrich, J. Hazard. Mater. 307, 302 (2016)

11. E. K. Addai, G. Dieter, K. Ulrich, J. Hazard. Mater. 301, 314 (2016)

12. M. Półka, Sz. Ptak, Procedia Engineering 192, 743 (2017)

13. PN-EN 50281-2-1:2002 